\title{
Review of Visceral Surgery Activities in A Field Hospital in Juba: Epidemiological, Diagnostic and Therapeutic Aspects
}

\author{
Abdessamad El Kaoukabi*, Mohamed Belhamidi, Hicham Krimou, Nabil Jbili, Samir Hasbi, Mohamed \\ Menfaa, Fouad Sakit and Abdelkrim Choho
}

Visceral surgery, Sidi Mohamed Ben Abdellah University, Morocco

*Corresponding author: Abdessamad EL KAOUKABI , visceral surgery department, Moulay Ismail military Hospital, Morocco.
Received Date: July 15, 2019

Published Date: July 25, 2019

\begin{abstract}
To perform an epidemiological review of the visceral surgery operative activity of the Juba Field Hospital (JFH). A total of 202 surgical procedures were retained. They represented $38.92 \%$ of operative activities. The emergencies were $12(13.33 \%)$. The first condition was hernias $114(60 \%)$ followed by proctologic conditions $45(23.68 \%)$. The average age of patients was 38, 75 years with extremes of 12 and 86 years. There were 150 males $(78,94 \%)$ and 40 females $(21.05 \%)$. The sex ratio is 3.75 . The evolution was favorable in $95 \%$ of the cases, the postoperative complications were $9.9 \%$ dominated by the suppurations of the operating site.
\end{abstract}

Conclusion: The visceral surgery activities are important in Juba with domination of the hernia pathology that must be treated early to prevent complications.

Keywords: Visceral surgery; Hernia; Field hospital; Juba

\section{Introduction}

As part of the South-South cooperation, King Mohammed VI gave his high instructions for the deployment of a multi-specialty field hospital in Juba with a capacity of 30 beds expandable to 60 , with a staff of 20 specialist doctors and 18 nurses. Visceral surgery was provided by a single general surgeon. We wanted to take stock of more than 3 months of visceral surgery activity. Thus, the purpose of this study was to describe the epidemiological aspects, diagnosis of visceral affections and report the results of the management.

\section{Materials and Methods}

This was a descriptive retrospective study over a period of more than 3 months from January 15 to April 25, 2017. Included were all patients operated on for a visceral pathology in the operating theater of the Juba Field Hospital. The operating theater of the JFH is equipped with 2 rooms for surgical procedures, including one reserved for minor surgery such as circumcisions, incisions and drainages of abscess, uterine curettage for incomplete abortions, lipomas and cyst resections under local anesthesia. The patients had been operated on by a general surgeon. The sources of the data were the registers of operative protocols and hospitalizations. The variables studied were sociodemographic, diagnostic and therapeutic outcomes.

\section{Results}

\section{Epidemiology}

During the study period, 519 patients were operated in the operating theater of the JFH including 202 (38.92\%) for a visceral pathology. The average age of patients was 38.75 years with extremes of 12 and 86 years. There were 156 males (77.22\%) and 46 females $(22,77 \%)$. The sex ratio is 3.39 . Scheduled surgery and emergencies concerned 190 (94.05\%) and 12 (5.94\%) patients, respectively. 


\section{Diagnosis aspect}

The first two pathologies in order of frequency were hernias and proctologic pathologies (Table1). Surgical emergencies involved 12 patients (5.94\%) including 6 appendicitis (2.97\%) and 6 cholecystitis $(2.97 \%)$. The inguinal hernias (Figure 1) accounted for $80.70 \%(n=92)$ of the hernias and $45.54 \%$ of the operated diseases. The femoral hernias (Figure 2) were 2 (0.99\%). The epigastric (Figure 3) and incisional hernias were 19 (9.40\%) and $1(0.49 \%)$, respectively and there were 12 (5.94\%) uncomplicated vesicular lithiasis. Only one patient was treated for hydatid liver disease $(0.49 \%)$.

Table 1: Distribution of Pathologies Operated in the Operating Room.

\begin{tabular}{|c|c|c|c|}
\hline Proctologic pathologies & Number & Percentage & Middle Age \\
\hline Appendicitis & 6 & 2,97 & 31,6 \\
\hline Cholecystitis & 6 & 2,97 & 31,3 \\
\hline Inguinal Hernia & 92 & 45,54 & 43,4 \\
\hline Femoral Hernia & 2 & 0,99 & 40 \\
\hline Epigastric Hernia & 19 & 9,40 & 45,6 \\
\hline Incisional Hernia & 1 & 0,49 & 49 \\
\hline Vesicular Lithiasis & 12 & 5,94 & 43,3 \\
\hline Hydatid Cyst Of The Liver & 1 & 0,49 & 36 \\
\hline Proctology & 57 & 28,21 & 35,55 \\
\hline Lipomas & 8 & 03,96 & 38,3 \\
\hline
\end{tabular}
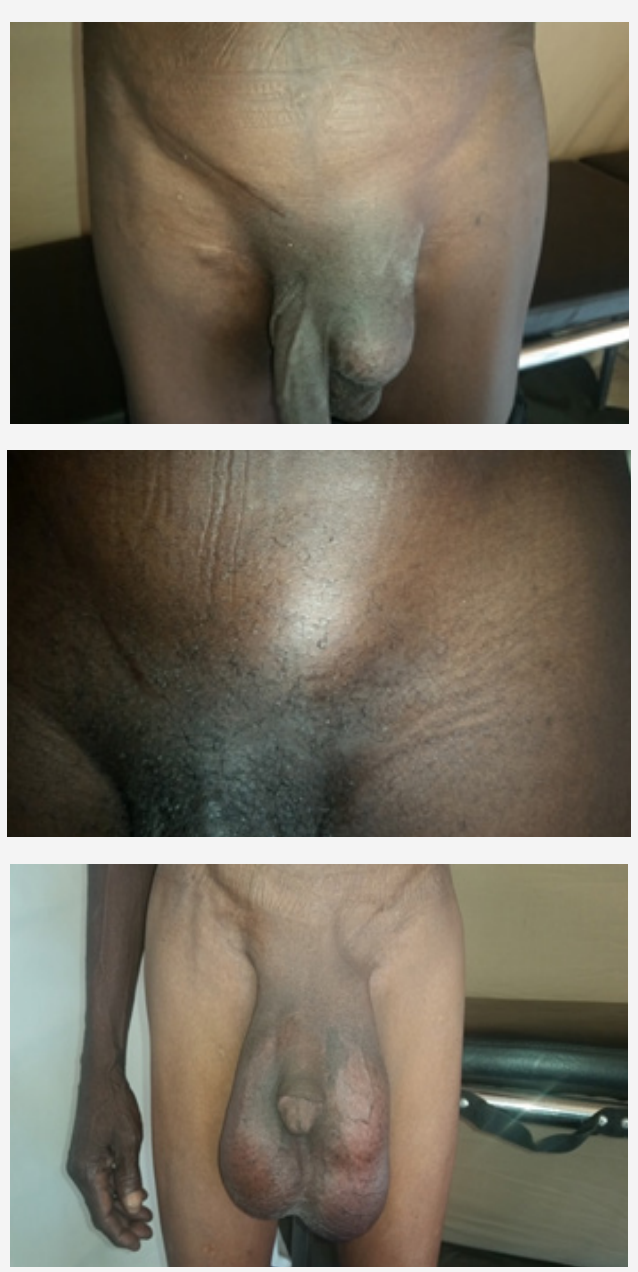

Figure 1: Inguinal Hernias.

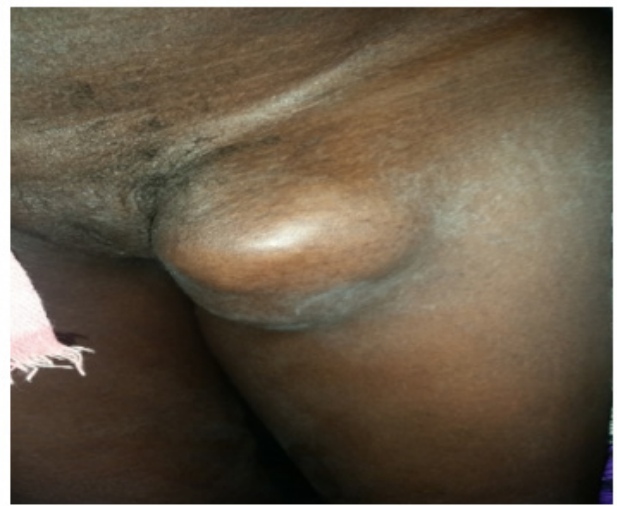

Figure 2: Left Femoral Hernia.

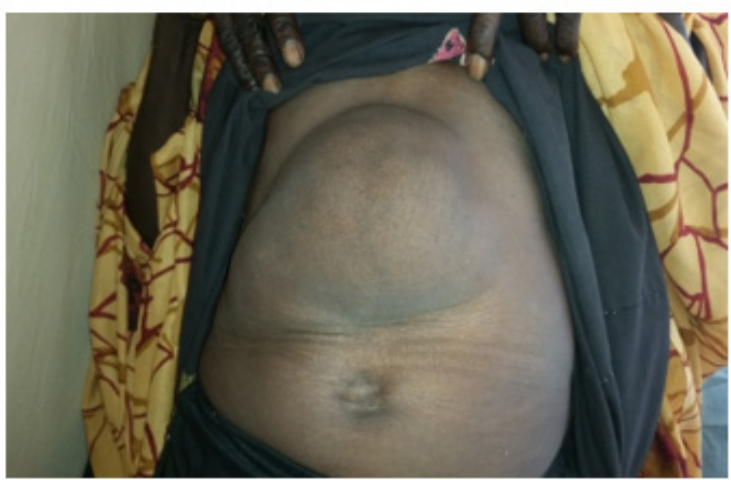

Figure 3: Epigastric Hernia.

\section{Therapeutic results}

We recorded 20 cases of complications, a morbidity of $9.90 \%$. Surgical site infections were 14 or $6.93 \%$ of all surgical procedures and $70 \%$ of complications. Other complications were: scrotal hematoma 03 cases (1.48\%), parietal hematoma 02 cases $(0.99 \%)$. A single stercoral fistula was recorded $(0.45 \%)$.

\section{Discussion}

Visceral surgery accounted for $38.92 \%$ of the operations of the JFH operating theater and involved more young males. Emergencies accounted for $11.88 \%$ of visceral surgery activities. The young age of the population has been found in several studies concerning visceral surgery [1-7]. Groin hernia is a surgical pathology whose frequency makes it one of the first acts of general surgery [8]. Even if its prevalence and incidence are not known, hernia occupies first place visceral pathologies In Africa [9]. This high rate of hernia surgery can be explained by the strong presence of farmers in this rural area. Sani R. and al in Niger also found a predominance of hernia surgery in a study conducted in several area hospitals [7]. Inguinal hernias accounted for $45.54 \%$ of pathologies. This rate was well above the $15.3 \%$ found in Dakar [10]. Acute appendicitis seems rare with $2.97 \%$ of visceral surgery activities. Patients are seen at an early stage which explains the absence of complications contrary to what has been observed by other authors in Africa $[1,3,7]$ where patients are seen at the stage of complication which explains the high percentage of appendicular peritonitis $(15,26 \%)$. 
In western countries, acute appendicitis accounts for 7 to $14 \%$ of UCA [11]. A study conducted in the same hospital in 2016 found a rate of $10 \%$ [12]. The rate of surgical site infections was $6.93 \%$. This rate varies from $2.5 \%$ to $30.90 \%$ in Africa according to countries and years [13] for all surgical procedures. It was 7.3\% in Parakou in northern Benin in 2011 [14]. The mortality rate was $00 \%$ compared to $6.25 \%$ found in Niger [7].

\section{Conclusion}

The visceral surgery at the JFH (Juba field hospital) are dominated by hernia surgery and proctologic surgery. The absence of traumatic abdominal surgery was mainly due to the site of the hospital in central Juba far from unstable areas.

\section{Acknowledgement}

None.

\section{Conflict of Interest}

No conflict of interest.

\section{References}

1. Harouna Y, Ali L, Seibou A, Abdou I, Y Gamatie, et al. (2001) Two years of emergency digestive surgery at National Hospital of Niamey (Niger): Analytical and Prognostic study Medicine of Black Africa 48(2): 49-54.

2. Ajao OG (1981) Abdominal emergencies in a tropical African population Br J Surg 68(5): 345-347.

3. Padonou N, Diagne Bandoye M, Cherbonnel GM, Nussaume O (1979) Non traumatic surgical abdominal emergencies at Dakar CHU: four-year statistic (1973-1976) Dakar Medical 24 (1): 90-97.

4. Kassegne I, Kanassoua KK, Sewa EV, Tchangari B, Sambiani DM, et al. (2013) Prize en charge des péritonites aiguës généralisées at the Center Hospitalier Universitaire by Kara Saranf 18(2):115-121.
5. Ouangre E, Zida M, Bonkoungou PG, Sanou A, Traoré SS (2013) Acute peritonitis generalized in rural Burkina Faso: about 221 cases. Rev Sante Cams 1(2): 75-79.

6. Harouna YD, Abdou I, Saidou B, Bazira L (2001) Peritonitis in tropical environment: etiological particularities and current prognostic factors: about 160 cases. Med Afr Black 48(3): 1035.

7. Sani R, Nameoua B, Yahaya A, Hassane I, Adamou R, et al. (2009) The Impact of Launching Surgery at the District Level in Niger. World J Surg 33(10): 2063-2068.

8. Pallas G, Simon F, Sckkeel P, Chapuis O, Jancovici R (2010) The inguinal hernia in Africa and laparoscopy: utopia or realism? J Afr Chir Digest 10(2): 1086-1089.

9. Ohene Yeboah M, Abantanga FA (2011) Inguinal Hernia Disease in Africa: A common but neglected surgical condition. West Afr J Med 30(2): 77-83

10. Konaté I, Cissé M, Wade T, Tendeng J, Sine B, et al. (2010) Management of inguinal hernias at the surgical clinic of Aristide le Dantec hospital in Dakar: a retrospective study of 432. J Afr Chir Digest Case 10(2): 10861089.

11. Flum DR (2015) Acute Appendicitis Appendectomy or the "Antibiotics First" Strategy. N Engl J Med 372(20): 1937-1943.

12. Tamou Sambo B, Hodonou AM, Allode AS, Mensah E, Youssouf M, et al. (2016) Epidemiological, Diagnostic and Therapeutic Aspects of Abdominal Trauma at Bembereke. North Benin European Scientific Journal 12(9): 395-405.

13. Nejad SB, Allegranzi B, Syed SB, Ellis B, Pittet D (2011) Health care associated infection in Africa: a systematic review. Bull World Health Organ 89(10): 757-765.

14. Hodonou MA, Hounkponou F, Allodé SA, Tobome SR, Fatigba OH, et al (2016) Bacteriological aspects of surgical site infections at the Borgou departmental hospital in Parakou (Benin) European Scientific Journal 12(9): 353-360 